\title{
BIOMASS DERIVED PRODUCTS AS MODIFIERS OF THE RHEOLOGICAL PROPERTIES OF COKING COALS
}

\author{
M.A. Diez ${ }^{1}$, R. Alvarez ${ }^{1}$ and M. Fernández² \\ 1Instituto Nacional del Carbón (INCAR), CSIC, Apartado 73, 33080 Oviedo, Spain \\ ${ }^{2}$ Centro Nacional de Investigaciones Metalúrgicas (CENIM), CSIC, Avda Gregorio del Amo 8, 28040 Madrid, Spain
}

\begin{abstract}
The modifications in the development of fluidity of a coking coal caused by eucalyptus wood and its carbonization products (charcoal and tars) were assessed by Gieseler plastometry. In addition, three biomass model compounds (cellulose, xylan and lignin) were selected for comparison with biomass products. Thermogravimetry was used to follow the pyrolysis behaviour of the biomass products and model compounds and to study the role of them in the reduction of coal fluidity.
\end{abstract}

Keywords: Coal, Biomass, Charcoal, Wood Tars, Co-pyrolysis, Thermogravimetry, Thermoplasticity

\section{INTRODUCTION}

Nowadays the environmental benefits of wood or other forms of vegetable biomass associated with the reduction of $\mathrm{CO}_{2}$ in the atmosphere is attracting wide attention due to its $\mathrm{CO}_{2}$-neutrality, its contribution to the preservation of natural resources and its flexibility in the production of solid, liquid and gaseous fuels. Biomass can be used in the production of chemicals and liquid fuels, charcoal for use in metallurgy, carbon adsorbents from wood and biomass wastes and for co-firing with coal in energy generation.

Currently, charcoal from hardwood species in small blast furnaces is being employed for iron production in Brazilian steel industry $[1,2]$. In the last few years, the use of charcoal from sustainable biomass in modern blast furnaces has given rise to an environmentally friendly option for reducing $\mathrm{CO}_{2}$ emissions and the use of fossil fuels $[3,4]$. In the steel industry, charcoal is also seen as a potential additive to coal blends in the production of coke used to feed blast furnaces [4].

The aim of this work is to study the thermal behaviour of biomass-derived pyrolysis products and their relevance to the evolution of volatile matter and the development of fluidity of coal during co-carbonization. These two interrelated phenomena at have been shown to be good parameters for a first evaluation of the performance of blends in cokemaking.

\section{EXPERIMENTAL}

A bituminous coal $(A)$ with $21.6 \mathrm{wt} \%$ volatile matter on a dry basis and with a medium Gieseler fluidity of $389 \mathrm{ddpm}$ was used as the basic component of the blends with eucalyptus wood and the pyrolysis products obtained at $415{ }^{\circ} \mathrm{C}$ (soak time $45 \mathrm{~min}$ ): charcoal (Ch) and the two tar fractions (water-soluble tar, ST and water-insoluble tar, IT). These were added to the coal $A$ in amounts of 2, 5 and $10 w t \%$. Three biomass model compounds (cellulose, xylan and lignin) were also tested.

Thermogravimetric analysis (TG/DTG) was conducted in a TA Instrument SDT2960 thermoanalyser. Samples of nearly $15 \mathrm{mg}$ were pyrolysed from ambient temperature up to $1000^{\circ} \mathrm{C}$ at $10^{\circ} \mathrm{C} / \mathrm{min}$ under a nitrogen atmosphere. The particle size used for the solid samples was $<0.212 \mathrm{~mm}$ (except for model compounds), the same used in the proximate and elemental analysis.

The thermoplastic properties of the coal and the blends were examined in a constant-torque Gieseler plastometer, R.B. Automazione PL2000 (ASTM D2639-04). The rotation of a stirrer placed inside a compacted $5 \mathrm{~g}(<0.425 \mathrm{~mm})$ sample was measured, while the sample was heated from $300^{\circ} \mathrm{C}$ up to $550^{\circ} \mathrm{C}$ at a heating rate of $3^{\circ} \mathrm{C} / \mathrm{min}$. The fluidity was recorded in dial divisions per minute (ddpm) as a function of the temperature.

For comparison purposes, fluidity measurements were also carried out with additional series of an industrial coal blend $B$ used for blast-furnace coke manufacture. In this case, the 
lower proportion of the biomass products (2 wt\%) was selected.

\section{RESULTS AND DISCUSSION}

\section{A. Main characteristics of coal and biomass products}

The solid (lump charcoal) and liquid products (watersoluble and -insoluble tars) obtained by carbonization at $415^{\circ} \mathrm{C}$ from eucalyptus wood were selected as potential additives for co-carbonization with a coking coal in the manufacture of coke. Table 1 shows the data from the proximate and elemental analysis of the coking coal $A$, the coal blend $B$, the eucalyptus wood and the woody biomass-derived products.

Table 1. Proximate and elemental analysis (expressed in a dry basis).

\begin{tabular}{lccccc}
\hline & Coal A & Blend B & SD & Ch & IT \\
\hline Ash (wt\%) & 9.0 & 8.1 & 0.28 & 0.37 & - \\
VM (wt\%) & 21.6 & 23.9 & 83.7 & 30.4 & - \\
C (wt\%) & 82.5 & 81.9 & 46.7 & 83.3 & 48.3 \\
H (wt\%) & 4.5 & 4.9 & 5.9 & 3.1 & 7.4 \\
O (wt\%) & 1.7 & 1.9 & 46.8 & 13.2 & 43.2 \\
\hline
\end{tabular}

Eucalyptus sawdust (SD) is characterized by a high volatile matter content, low carbon and high oxygen contents. Charcoal (Ch) with a higher carbon content still retains a high amount of oxygen in its chemical composition and an appreciable amount of tarry compounds. The insoluble tar, a viscous and dark red-brown colored liquid (IT), is characterized by a calorific value (HHV) of about $18 \mathrm{MJ} / \mathrm{kg}$, which is much lower than that of conventional fossil fuels (around $42 \mathrm{MJ} / \mathrm{kg}$ ). Its $C$ and $O$ contents is similar to that the raw material.

In contrast, the water-soluble tar (ST) is a complex mixture of water and highly condensed water-miscible oxygenated compounds. Due to the high amount of water and the low carbon content (13 $\mathrm{wt} \% \mathrm{db}$ ) in this soluble tar fraction, its calorific value is negligible.

\section{B. Pyrolysis behaviour of the coal and biomass products}

The evolution of the volatile matter (DTG) as a function of the pyrolysis temperature is shown in Figure 1.
For coking coal A most of the $\mathrm{VM}$ evolves $(14.8 \mathrm{wt} \%)$ in a temperature range of $400-600{ }^{\circ} \mathrm{C}$, reaching a maximum rate of volatile matter evolution at around $490^{\circ} \mathrm{C}$ (Tmax). At $1000^{\circ} \mathrm{C}$, the coke yield is nearly $78 \mathrm{wt} \% \mathrm{db}$.

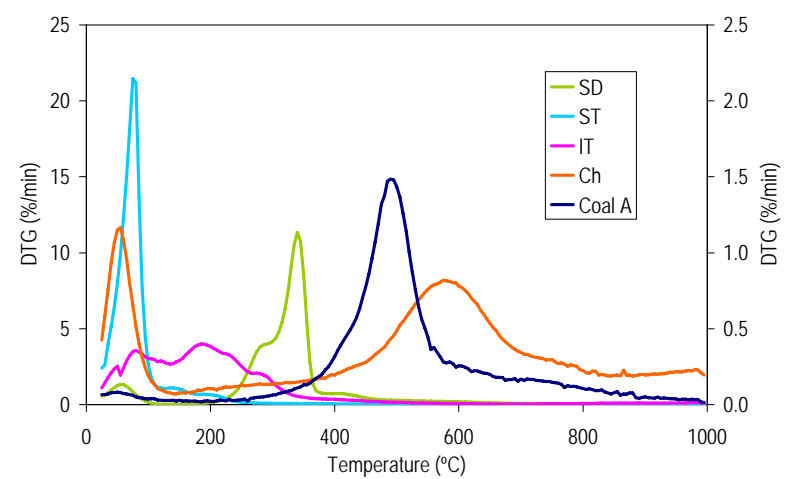

Figure 1. DTG of coal, eucalyptus sawdust (SD), charcoal (Ch) and water-soluble and -insoluble tars (ST, IT). (Left Y-axis for $\mathrm{SD}, \mathrm{ST}$ and IT; right $\mathrm{Y}$-axis for coal and $\mathrm{Ch}$ ).

The sawdust shows a typical hardwood profile with a low-temperature peak corresponding to the vaporization of water, plus two overlapping peaks of different DTG value at 280 and $340{ }^{\circ} \mathrm{C}$ which are assigned to the decomposition of hemicellulose and cellulose. There is also a flat tailing region above 400 ${ }^{\circ} \mathrm{C}$, corresponding to the slow decomposition of lignin over a broad temperature range [5], which contributes substantially to the formation of charcoal Compared to coal, sawdust yields large amounts of volatile products and its decomposition precedes the degradation of organic matter present in the coal. Nearly $87 \%$ of the total volatile products are released at a temperature $<400{ }^{\circ} \mathrm{C}$. This suggests that such compounds cannot have a positive synergic effect on the coal plastic stage.

This is also true in the case of the tars. ST which contains a large amount of water evolves up to $120^{\circ} \mathrm{C}$ arise of nearly $88 \%$. Insoluble tar, however, shows a different thermal behaviour. The components of IT distillate over a wider temperature interval, from ambient temperature to $400{ }^{\circ} \mathrm{C}$ (nearly $92 \%$ of the total volatiles).

In contrast, charcoal, after the stage of water evolution, initiates a stage of slow volatile matter release over a temperature range of $200-500{ }^{\circ} \mathrm{C}$, which is followed by an intensive VM release at higher temperatures (about $62 \%$ of the total volatile matter evolved). The temperature of maximum volatile matter release is $576^{\circ} \mathrm{C}$, which is significantly higher than the Tmax of the coal. This suggests that 
the decomposition of charcoal overlaps that of coal to a greater extent than that of other woody products.

\section{Influence of biomass-derived products on the fluidity of the coal}

Gieseler fluidity is one of the most important parameters for evaluating the coking ability of coal and for predicting coke quality. Biomass products reduce the coking capacity of coal and this is reflected by the decrease in Gieseler maximum fluidity (Fmax) (Figure 2). The extent of the reduction depends on the type of biomass product and the amount of biomass added.

Eucalyptus sawdust is the strongest modifier of coal fluidity, with a decrease in Fmax of the order of 54 to $97 \%$ for 2 and $10 w t \%$ additions. At all levels of addition, the effect of sawdust greatly resembles that of cellulose. Among the pyrolysis products of the eucalyptus wood, the insoluble tar influences the fluidity of the coal to a similar extent to cellulose, while the soluble tar (ST), possibly due to the high amount of water and hemicellulose derived products, causes the smallest decrease. Although its effect diminishes as the amount of ST increases in the blend. Charcoal has a moderate effect and shows a great similarity to the soluble tar at low addition rates. The less pronounced effect of charcoal may be associated to its double role: as an inert and as an active agent due to the desorption of tarry substances which block the fine structure of the charcoal.

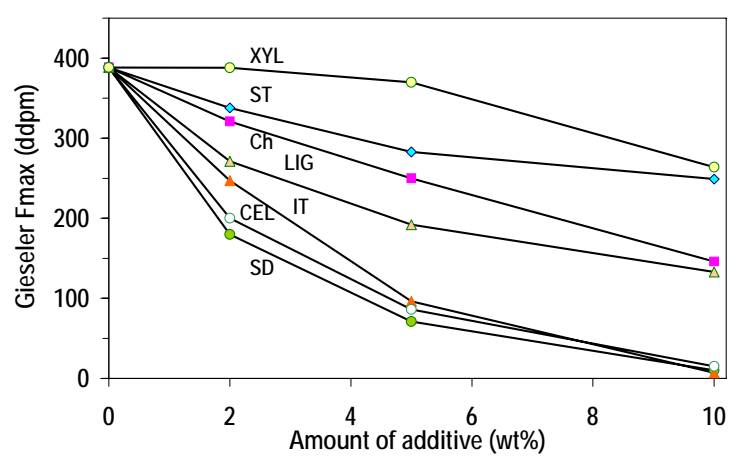

Figure 2. Variation of Gieseler fluidity (Fmax) of coal A with biomass and its carbonization products.

When lignin is added in a low concentration (2 wt\%), it has an effect somewhat analogous to that of IT, which is mainly composed of phenolic compounds generated during the decomposition of lignin. However, when high concentrations of lignin are present in the blend, the effect resembles that of charcoal. This is explained by the decomposition of lignin, which is partially volatilized in a phenolic tar that has similar composition to that of the IT fraction and partially transformed into char.

On the basis of the above results the following order from weak to strong effect of coal thermoplasticity is established:

$$
\mathrm{XYL}<\mathrm{ST}<\mathrm{Ch}<\mathrm{LIG}<\mathrm{IT}<\mathrm{CEL}<\mathrm{SD}
$$

This is also observed in the fluidity measurements carried out on several mixtures of an industrial coal blend (B) and its biomass products at an addition rate of $2 \mathrm{wt} \%$.

\section{CONCLUSIONS}

Except for charcoal, it can be seen that the thermal decomposition of woody biomass and its derived products occurs before the degradation of the coal structure. Charcoal shows a different behaviour and its thermal decomposition overlaps at a high temperature $\left(>500^{\circ} \mathrm{C}\right)$, just after the point of maximum coal devolatilization and during the transformation of the semicoke to coke. In all cases, biomass products and their components reduce the fluidity of the coal during thermal treatment between 300 and $550{ }^{\circ} \mathrm{C}$. The condensable gases released from the biomass and its products at different stages of coal pyrolysis are responsible for reducing the coking capacity of coal. Not only does the amount of such volatiles play an important role, but their composition is also a critical factor. In general, the overall effect of biomass products greatly resembles that of the parent biomass component.

\section{REFERENCES}

[1] Campos Ferreira $O$ (2000). Emission of greenhouse effect gases in vegetal coal production, Economy \& Energy 21.

[2] FAO Forestry Department (1986). Industrial charcoal making. Paper 63.

[3] Ultra-low $\mathrm{CO}_{2}$ steelmaking (ULCOS), http://www.ulcos.org.

[4] Hanrot F, Sert D, Delinchant J, Pietruck R; Bürgler T, Babich A, Fernández M, Alvarez R, Diez MA (2009). $\mathrm{CO}_{2}$ mitigation for steelmaking using 
1st Spanish National Conference on Advances in Materials Recycling and Eco - Energy Madrid, 12-13 November 2009

S01-1

charcoal and plastics wastes as reducing agents and secondary raw materials, $1^{\text {st }}$ Spanish National

Conference on Recycling Materials an ECo-Energy.(RECIMAT'09) (2009), Ed. F.Puertas, F.J.Alguacial, A.Guerrero and F.A.López. pp. 181-184

[5] Caballero JA, Marcilla A, Conesa JA, (1997). Thermogravimetric analysis of olive stones with sulphuric acid treatment J. Anal. Appl. Pyrol. 44, 75-88. 